\title{
Schools as Learning Organizations: Impact of Age \& Experience of Preschool Teachers understanding about Disciplines of Learning Organization in Peter Senge's Model
}

Dr. Sumaira Noreen ${ }^{1}$

Sadia Shahbaz ${ }^{2}$

\author{
Journal for Educators, Teachers and Trainers, Vol. 12 (1) \\ https://jett.labosfor.com/
}

Date of reception: 16 September 2020

Date of revision: 13 Dec 2020

Date of acceptance: 12 March 2021

Dr. Sumaira Noreen, Sadia Shahbaz (2021). Schools as Learning Organizations: Impact of Age \& Experience of Preschool Teachers understanding about Disciplines of Learning Organization in Peter Senge's Model. Journal for Educators, Teachers and Trainers, Vol. 12(1). 37 - 47.

\footnotetext{
${ }^{1}$ Assistant Professor, History Department, Lahore College for Women University, Lahore, Pakistan ${ }^{2}$ Campus Head, Silver oaks international school, Lahore
} 


\title{
Schools as Learning Organizations: Impact of Age \& Experience of Preschool Teachers understanding about Disciplines of Learning Organization in Peter Senge's Model
}

\author{
Dr. Sumaira Noreen ${ }^{1 *}$, Sadia Shahbaz ${ }^{2}$ \\ ${ }^{1}$ Assistant Professor, History Department, Lahore College for Women University, Lahore, Pakistan \\ ${ }^{2}$ Campus Head, Silver oaks international school, Lahore \\ *Corresponding Author \\ Email ID: sumaira.noreen@lcwu.edu.pk, sumfaheem@googlemail.com.
}

\begin{abstract}
This survey research was designed to notice the impact of age and teaching experience of preschool teachers on their perceptions of Peter Senge's learning organization concept of five disciplines. The questionnaire was based on Gravin's tool kit (2008) that was originally being designed for assessing the working of any learning organization. Out of 350 respondents from 10 branches of a private school in Lahore, 300 pre-school teachers had responded back. When analyzed individually, the effect of age and experience about awareness of five disciplines showed a varied response in results but an understanding about Senge's five disciplines was there in the responses of sample teachers. Data findings revealed that while a comprehensive understanding about all the five disciplines of Peter Senge's model was not up to the mark, some evidence about their understanding was still commendable because the concept is still emerging in context of Pakistan.
\end{abstract}

Keywords: Learning Organisation, School Teachers, System Thinking, Shared Vision, Personal Mastery, Mental Model, Team Learning

\section{INTRODUCTION}

Since late 1930s, the concept of Learning Organization has been in vogue and so has been discussions about making schools as Learning organisations. According to Senge (2000), schools are integral part of our society and are learning organizations who strive to excel in the field of education and to move with the society in which they are formed. Schools are also focused to stay up to date and move with the ever-changing world of globalization. A lot of time, energy, effort and resources are needed to convert any school into a genuine and sustainable learning organization. (Fullan, 2018). And when it comes to making any school a learning organisation, the role of teachers become significant. But the question is to what extent teachers are well acquainted with the idea of learning organization that strive for creating and implementing new ideas in learning. In this reference, Peter Senge's seminal work, 'The Fifth Discipline' has been adopted in this study for the sake of operationalizing the constructs of teachers' understanding about the constructs of schools as Learning Organisations. The main focus of the study is to check the perception and understanding of preschool teachers as Schools as a Learning Organization under the five disciplines of Peter Senge's Model.

\section{LITERATURE REVIEW}

Peter Senge defined learning organization as 'organizations where people continually expand their capacity to create the results they truly desire where new and expansive pattern of thinking are nurtured where collective aspiration is set free and where people are continually learning to see the whole together' (Senge, 1990). Learning Organization can be interpreted as- An Organization in which group of people work with collaboration and co-operation to achieve common goals and set best standards for the future, then strive to maintain it effectively within their cultural settings. 
Senge's Model is of primary focus and provides a reference point and chief source of information to the study. But the concept of Learning Organization has a strong history back from 1930's which must be discussed briefly: The word Learning Organization originated in the year 1938 when John Dewey talked about "experimental learning". He also wrote a book on experimental learning based on the cyclical learning changes, a detailed description that is required by any organization (Dewey, 1938). After this a psychologist Kenneth Craik introduced the word "Mental Models" in 1940's, he states that mental model is the sense of expressing your views, opinions, thoughts clearly and boldly to others.(Craik, 1940). Kurt Lewin presented a point that a person's vision and real life show an existence of a relation between the both which need to be openly expressed in any organization (Lewin, 1946).

In 1947, Margaret Mead and Lawrence Kubie brought the term "System Thinking" in the field of organization. Jay Forrester (1956) developed the notion of "System Dynamics" and started working on its different dimensions. In 1960, Douglas McGregor wrote a book in which he explained that different perceptions of a person's insight must be opened up in the organization for growth and expansion of the employees and the organization, both (McGregor, 1960). In 1961, Jay Forrester published a book "Industrial Dynamics", his very first prime application to dynamics of system in organizations. Another book entitled "Urban Dynamics" was published with the introduction of new idea of "Shifting the burden" by the writer Jay Forrester (1969). Chris Arygyris and Donald Schon (1970) started working together in "Action Science", another move towards the clarity of "System Thinking". Don Michael wrote a worth read book "Learning to plan and planning to learn" in 1973 which promoted the idea of "Organizational Learning”. In 1974, Arygyris and Donald Schon published a book named as "Theory in Practice'

From 1930's till 1970's, all the researchers and educationists worked with system dynamics or system thinking, creative tensions now known as personal mastery, mental models their needs and implementation in creating, building and above all sustaining an organization. Then a progression started in the field of learning organization when Peter Senge, student of Jay Forrester actually formed a learning organization in 1984. He studied in group and later in 1987; he presented his views in an article in Harvard Business Review entitled as "Planning as Learning" in which he stated "The greatest competitive advantage for any organization is its ability to learn". Although it was Senge's combined effort with his colleagues but he introduced the term Learning Organization and opened up a whole new avenue for many educators and companies. He not only merged the different scattered ideas of many researches but also provided a new and authentic dimension to the concept of learning organization. Senge notified to the world that learning is fundamental for any organization either it's a bank, industry, business or school; learning is a must.

Ultimately, Peter Senge published a classic book in 1990 "The Fifth Discipline" which changed and explained the concept of learning organization in a new, reformed and refined manner. Moreover, the five disciplines explained in this book got more attention than any others work. In fact many researchers use these five disciplines as a framework for their study. These five disciplines are: Personal Mastery, Mental Model, Shared Vision, Team Learning and System Thinking. Peter Senge (1990) suggested that organizations may discard and remove evident "learning disabilities" and begin to be able of learning only when they try to gain control of all the five disciplines. Senge (1990) defined the actual or dream learning organization as a set pattern of how the successful organizations must be constructed if attainment of maximal learning is required and taken as prime focus. The conceptualization of a perfect learning organization acquired a lot of attention in the late 1980's gained fame in late 1980's in United States of America (USA) despite the fact that prior considerable thinking was assembled and based on the system theory. The learning procedures are growing, developing, adapting and learning which underlie healthy, adaptive survival.

In the almost last two decades after the publication of a masterpiece book of Peter Senge in 1990 - The Fifth Discipline: "The Art and Practice of the Learning Organization", an uprising issuance (Ching-wen Cheng, 2009) of "learning organization" began to be a recognizable vogue for the pedagogical zone of organization growth and expanse. All the directors and labor from all regions around the chief business heads are worried and anxious to induce new strategies and approaches to upgrade and refine their organization for success. As stated by (Drucker, 1998), the conception of an ideal "learning organization" additionally and must incorporate all the educational institutes and organizations; as all the educational institutes and organizations show an ever growing requirement calls for its more effective running in a competitive and ever-changing domains of learning environment. To cope up with the swift pace, competitive period throughout the world, learning is the sole tool 
for one's outlast survival and similar is for the educational and technological world. There is no doubt and uncertainty that the all the educational institutes must for see on becoming a prosperous learning organization, modify and change themselves into a successful and ideal learning organization to supply a constant series for the progress and upgradation procedure to encounter the upcoming future needs, demands and challenges. In context of Pakistan, the concept of learning organization appears to be unfolding and latest. Since, it is a western concept and still in advancement in many countries also picking up strength in Pakistan on a very slow pace and this research focuses more to know that whether the schools of Pakistan have any concept of learning organization and portrays any culture of an ideal learning organization. The purpose and scope of this study is to focus on a private institute of Lahore, Pakistan.

It is being hypothesized that there are no set designs, pattern and rules to build and create an ideal learning organization (Cavaleri, 2008) which serves as a footpath or perfect example for others. This generally shows that an immeasurable and extensive variety of strategies and approaches are being used based on divergent understandings, thoughts, ideas, views and perceptions of why it is needed to become a learning organization. Learning organization can be defined as a one structure (Emery, 1993) in which all its members are capable of learning and try to learn continuously within it. The organizational infra structure of any organization itself provides an ambiance for the continuation of education. Organizational learning, a very common word and an old concept but it had been observed that this topic shows slight concordance with learning organization when it comes to the definition, approach, view point, concepts and strategies. In duration of scrutinizing the similarities linking the two eminent streams of hypothesizing in the main area and attempt to separate the two eminent streams is still in process of research (Eric W.K.Tsang, 1997). The initial stream, approaches in writings are dealing with the query "How should an organization learn"? By selecting practitioners relying on communicative experiences and very often come after meticulous research strategies. The later stream on organizational learning deals with the query "how an organization learns?" The second stream tackles the hunger for scientific accuracy with the academics. If we spot the original view point of a perfect learning organization, it recommends that for any organization a specific pattern of inner governance is needed to be enrolled as a learning organization (Goh, 1998). The author attempted to narrate the model of administrative practices or methodologies which are basic for building up an ideal learning organization in his research.

\section{Problem Statement:}

Much research has been done in the field of schools as learning organization in western countries. There are so many articles and journals related to schools as learning organization e.g. "The application of learning organization to enhance learning in Singapore Schools" by Kala s. Ratna \& Pak Tee Ng (2016). This research also proved that application of learning organization model in the schools is an effective way of making them a successful learning organization and it will also increase the learning of teachers, students and parents. Though they used different models of learning organization in different schools of Singapore but the conclusion was that any model will yield a learning organization but implication of a model is a must. In another journal published in 2010 by Halia Silins \& Bill Mulford - "Schools as learning organization - Effects on Teacher Leadership and Student's Outcomes", a path model is used to assess the performance of school, working of teachers and the results of students. Recently, the case of understanding schools as learning organisations has also been taken up in Pakistan. For instance, the study of Zubeda Bana (2014) on public schools of Pakistan also concluded that there is a great need of reforms and interventions to label Pakistani schools as learning organizations. Saying this, there case of Pakistani schools as learning organisations is highly underrepresented in the literature. It is with such zeal that the present study has been taken up.

\section{Research Question}

Whether age and experience of teachers has an impact on their perceptions of schools as learning organization?

\section{OBJECTIVES OF THE STUDY}

The main objectives of this study are:

1- To identify what aspects of learning organization as Peter Senge's model depicts can be traced in teacher's responses.

2- To find out if there exist any variation in the learning organization patterns as depicted through teacher's responses of Peter Senge's Model among preschool teachers 
3- $\quad$ To analyze whether age and experience of teachers had any impact on their perception of learning organization

\section{OPERATIONALISATION OF KEY TERMS/VARIABLES OF THE STUDY:}

Learning Organization can be more elaborated as- An Organization in which group of humans work with collaboration and co-operation to achieve common goals and set best standards for the future, then strive to maintain it effectively within their cultural settings. Another definition of learning organization is "Organizations where people learn and adapt new changes, then implement those changes according to the needs of the society and work hard to maintain their performance". The concept of learning organization reached at the peak in early 1990's and the credit goes to Peter Senge who wrote "The Fifth Discipline" book on learning organization. The five disciplines mentioned in this book are the baseline for this research.

System thinking is attaining knowledge about the link and set patterns inside the entire system's order to modify them with equilibrium. Personal mastery is about paying particular attention in one's own capabilities and vitality, working as a creator with an artistic instinct, continuous edification; improving and escalating own personal thoughts and vision. Mental model signifies perceptions effecting subconscious about one's reaction to the outer world. Shared vision is developed by bridging up everyone's ideas for the organization's upcoming future. Team learning is erupting expertise in fortifying the intellect and execution of performances of all is huge than the aggregate of the each individuals thinking and efforts, it is achieved by thinking together and working together initially as a collaborative team. These five disciplines have become center of attraction for schools striving to become effective learning organizations. These disciplines lay a foundation in building up a school's vision to become a well reputed learning organization, to sustain the school standards according to the cultural needs of the society and the world.

\section{METHODOLOGY AND SAMPLE}

The study relied on the quantitative research approach as the result is required in numerical form to ensure the accuracy of the research in a quantifiable expression for future researchers. By definition, quantitative research is the collection and analysis of numerical data to describe, explain or predict different phenomena (Gay, Mills \& Airasian, 2014). The above definition clearly justifies the reliance of this research on quantitative research approach.

Survey research was being conducted as it is the best tool for quantitative research because it targets the specific audience more effectively to gather information in a numerical form. Surveys are beneficial for attaining factual information, data on attitudes and beliefs, preferences and predictions, opinions and perceptions, behaviors and experiences - both present and past (Weisberg 1996: Aldridge and Levine, 2001)

Ten branches of a private school system of Lahore city were taken as the population of the study. Only preschool teachers from all these branches were taken as the population of this study. The respondents of the study were all females because mostly female teachers work in preschool. The total preschool teacher's population in each branch varied from 35 - 40 in 2017 depending upon the sections in preschool. The total number of teachers working in the above mentioned 10 branches was almost 350 at that time (2017). I was able to retrieve 300 responses from teachers.

The sampling strategy is based on purposive sampling as the entire population of preschool teachers. The preschool teachers were requested to fill up the questionnaire. The researcher received 300 questionnaires from all the branches. A previously used questionnaire was pilto-tested and reformed for this survey to sum up and score the answers of the respondents. The only instrument of data collection was a questionnaire based on the 5 disciplines of Peter Senge's Model of Learning Organizations. For the sake of eliciting opinions from teachers, the researcher used a Likert-scale questionnaire from which the respondents will choose the option that best suits their opinion. Because 5 point Likert scale will assure the accuracy of attitudes, beliefs and behaviors of respondents.

The questionnaire covered up all the five disciplines of Peter Senge's Model. The items of the survey questionnaire were selected carefully from an old questionnaire to ensure the reliability of the whole research and then pilot testing of the questionnaire was also done in another branch of the same school system.

- $\quad$ Personal mastery - 4 items

- $\quad$ Mental models - 3 items 
- $\quad$ Team learning - 4 Items

- $\quad$ System thinking - 3 items

The questionnaire was of total 18 items and as the questionnaire was reformed using an old questionnaire from a previously done research so pilot testing was a must to check the reliability as the whole research is dependent on this survey questionnaire. For this purpose 30 preschool teachers from one branch were requested to fill up the survey questionnaire. This branch was not taken in the original sample later. The result of pilot testing showed highly reliable significant value of @ i.e. 0.811 , which ensured the use of the made questionnaire to be used as a tool in this research study. The population for pilot testing sample was 30 .

Table 1: Reliability Statistics of Pilot Testing

\begin{tabular}{|l|l|}
\hline Cronbach's Alpha@ & No. of Items \\
\hline .811 & 18 \\
\hline
\end{tabular}

According to the table given below, the Cronbach alpha value i.e. 0.811 of pilot testing falls in the good category and the instrument being used for this research is a good source for reliability and authenticity of this research.

Note: The Cronbach's alpha of reliability coefficient for any research ranges normally between 0 and 1. It estimates the internal consistency reliability of any of the research instrument used to get valid results of any research. According to the rule of "George and Mallery (2003)"

The researcher went to each branch personally and asked the preschool teachers to fill up the questionnaire. The teachers were requested to return the questionnaire within 3 to 4 days in the main office. The researcher collected the filled up questionnaire from main office of each branch. The researcher was able to get the questionnaires completely filled.

The data was entered in to a computer software SPSS (Statistical Package for the Social Sciences) for further analysis. Mean, Standard deviation and one way ANOVA were applied. Mean results could simply check the percentage of awareness of the concept of learning organization among preschool teachers. Mean was also applied to get the percentage of age and experience of all the preschool teachers. Standard Deviation ensures the best measure of variation among the perception of the preschool teachers. One way ANOVA was applied to determine that the data is statistically significant or not and if it shows statistically significant result, we accept the hypothesis and it means that there are at least two groups in our data which are statistically significant at some point. It is important to mention here that One Way ANOVA cannot tell at which point or level the groups were statistically significant. For this purpose, the researcher had to apply Post hoc Test; this test is only applied when the overall ANOVA result is significant. There are number of Post hoc tests but in this research when the data meets the significant Cronbach alpha value, Post Hoc Tukey's HSD is being applied to determine the difference between five disciplines, at which age group and in which experience level all the branches show significant results.

\section{DATA ANALYSIS OF AGE AND EXPERIENCE}

All the participants were female and preschool teachers. The table shows the age and experiences of teachers by percentage. The maximum number of 52 teacher's age limit lies between the $2-5$ years and 66 teachers are among age of 21 to 30 years which means that most of the preschool teachers are youngsters because the maximum calculated experience is also between 2 to 5 years. 27 teachers are of $31-40$ years of age. 21 teachers fall in the $6-10$ years of experience. 19 teachers have less than 1 year of experience. The teachers having more than 10 years of experience show a nominal value of 8 and $31-40$ years of teachers are just 7 .

Table 2: Distribution of participants by Age and Experience

\begin{tabular}{|l|l|l|l|}
\hline Variables & Levels & F & $\%$ \\
\hline Age(year) & & & \\
\hline & $21-30$ & 196 & 66 \\
\hline & $31-40$ & 82 & 27 \\
\hline & $41-50$ & 22 & 7 \\
\hline & & & \\
\hline
\end{tabular}




\begin{tabular}{|l|l|l|l|}
\hline Experience (years) & & & \\
\hline & $\leq 1$ & 58 & 19 \\
\hline & $2-5$ & 156 & 52 \\
\hline & $6-10$ & 63 & 21 \\
\hline & $>10$ & 23 & 8 \\
\hline
\end{tabular}

\section{ANOVA by age groups}

ANOVA when applied on all the five disciplines by age groups of preschool teachers of 10 branches of Lahore Grammar School show the following result. The ANOVA value of all the five disciplines show that mental model and shared vision are significant among teachers and rest of the three disciplines personal mastery, team learning are less significant, system thinking showed least significant value among different age groups of teachers.

Table 3: ANOVA for five disciplines of peter Serge's model among age groups

\begin{tabular}{|l|l|l|l|l|l|l|l|l|l|l|}
\hline & \multicolumn{2}{|l|}{$21-30$} & & \multicolumn{3}{|l|}{$31-40$} & & \multicolumn{2}{|l|}{$41-50$} & \multicolumn{2}{l|}{ ANOVA } \\
\hline & $\mathrm{M}$ & $\mathrm{SD}$ & & $\mathrm{M}$ & $\mathrm{SD}$ & & $\mathrm{M}$ & $\mathrm{SD}$ & $\mathrm{F}(2.297)$ & $\mathrm{P}$ \\
\hline Personal Mastery & 4.01 & .57 & & 4.11 & .59 & & 4.24 & .50 & 2.16 & .117 \\
\hline Mental Model & 4.01 & .70 & 4.23 & .56 & & 4.12 & .54 & 3.38 & .035 \\
\hline Shared Vision & 4.12 & .52 & 4.18 & .54 & & 4.42 & .54 & 3.31 & .038 \\
\hline Team learning & 3.91 & .67 & 4.05 & .59 & 4.07 & .50 & 1.65 & .194 \\
\hline System thinking & 2.63 & .43 & & 2.64 & .47 & & 2.69 & .39 & .19 & .826 \\
\hline
\end{tabular}

$\mathrm{P}<.05$ significant

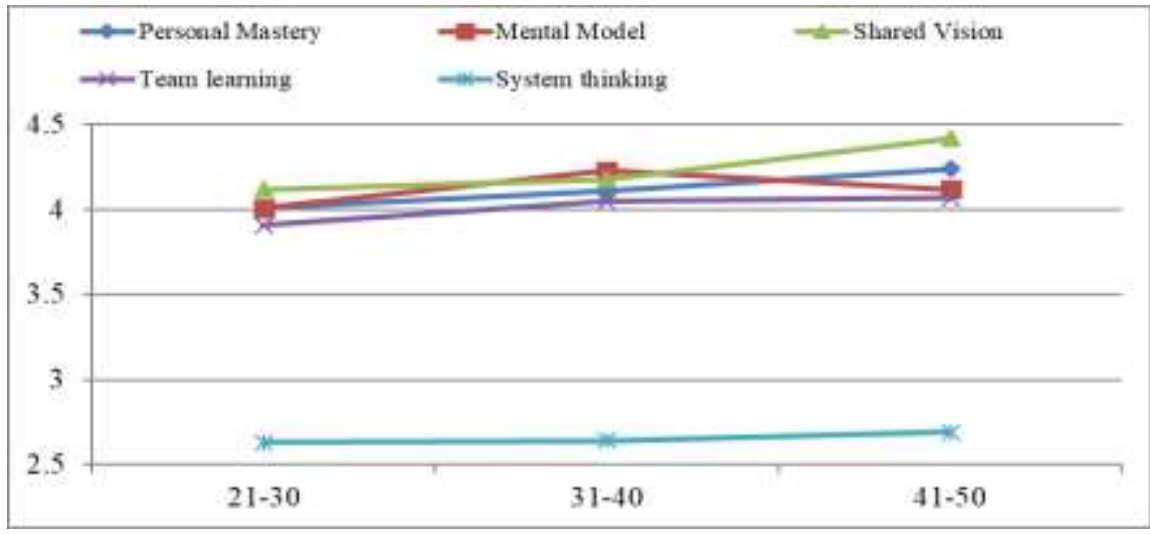

Fig.1: Linear graphs for five disciplines of Peter Senge among age groups

\section{ANOVA by experience}

The five disciplines of Peter Senge model were also analysed by different experiences of preschool teachers by applying ANOVA. The results of ANOVA values on five disciplines of Peter Senge Model show that shared vision and team learning are significant. Personal Mastery is significant to some extent. Mental Models and System Thinking are less significant by experience of the preschool teachers.

Table 4: ANOVA for five disciplines of peter Serge's model among different experiences of participants

\begin{tabular}{|l|l|l|l|l|l|l|l|l|l|l|l|l|l|}
\hline & \multicolumn{2}{|l|}{$\leq 1$} & \multicolumn{2}{l|}{$2-5$} & & \multicolumn{2}{l|}{$6-10$} & & $\geq 10$ & \multicolumn{2}{l|}{ ANOVA } \\
\hline & $\mathrm{M}$ & $\mathrm{SD}$ & $\mathrm{M}$ & $\mathrm{SD}$ & & $\mathrm{M}$ & $\mathrm{SD}$ & $\mathrm{M}$ & $\mathrm{SD}$ & $\mathrm{F}(3,296)$ & $\mathrm{p}$ \\
\hline Personal Mastery & 3.97 & 0.62 & 4.09 & 0.53 & & 3.96 & 0.63 & 4.25 & 0.53 & 2.22 & 0.086 \\
\hline Mental Model & 3.93 & 0.72 & 4.10 & 0.69 & 4.13 & 0.52 & 4.16 & 0.56 & 1.37 & 0.253 \\
\hline Shared Vision & 4.06 & 0.58 & 4.16 & 0.51 & 4.15 & 0.54 & 4.42 & 0.46 & 2.69 & 0.046 \\
\hline Team learning & 3.72 & 0.71 & 4.00 & 0.62 & & 4.06 & 0.65 & 4.05 & 0.49 & 3.64 & 0.013 \\
\hline System thinking & 2.56 & 0.46 & 2.67 & 0.41 & & 2.62 & 0.47 & 2.70 & 0.41 & & 1.00 & 0.392 \\
\hline
\end{tabular}




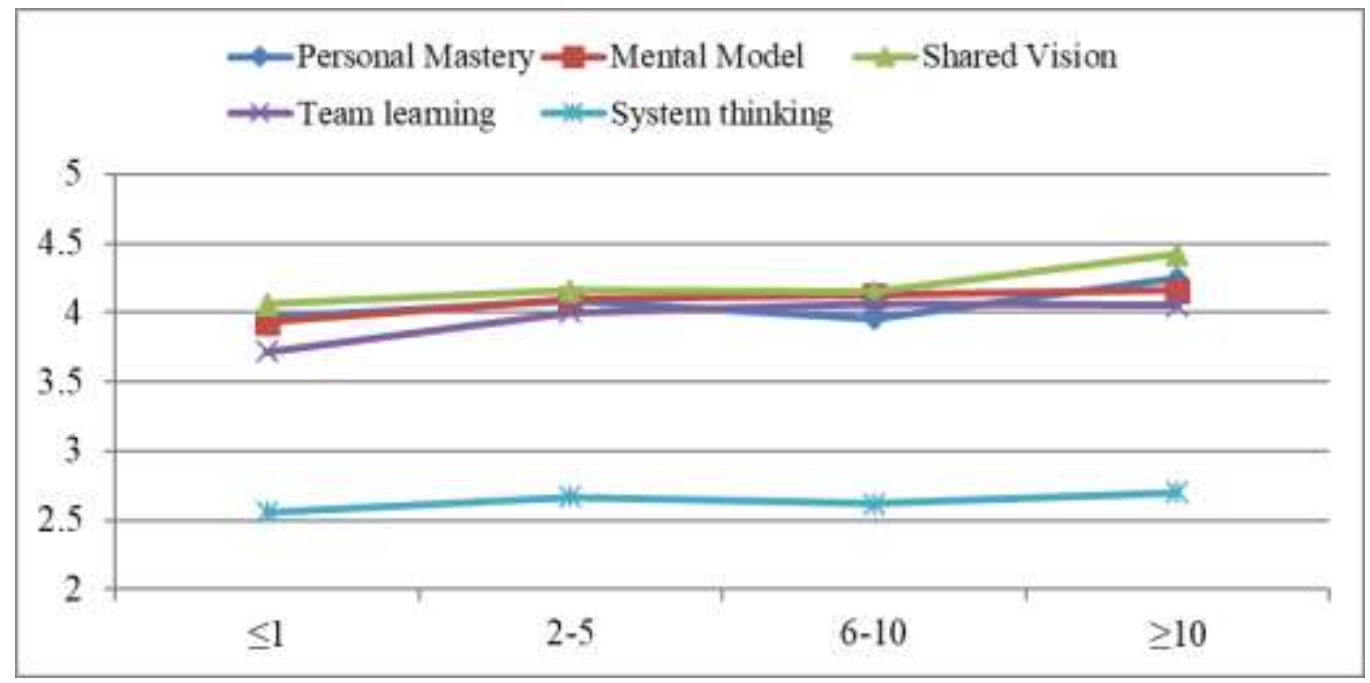

Fig.2: Linear graphs for five disciplines of Peter Senge among experiences of participants

The Post Hoc Tukey by age groups and experience of teachers

The Post Hoc Tukey Test is then applied to compare the means because the overall value of Cronbach alpha is significant. It should be noted that Post Hoc is only applied when the ANOVA value is statistically significant and Post Hoc Test is always used to confirm where the difference occurred between the groups.

Table 5: Post Hoc Tukey HSD for pairwise comparison among age groups on disciplines of peter Serge's model

\begin{tabular}{|l|l|l|l|l|l|}
\hline Dependent Variable & Age (I) & Age (J) & Mean Diff. (I-J) & SE & p \\
\hline Mental Model & $21-30$ & $31-40$ & $-.22\left(^{*}\right)$ & .09 & .028 \\
\cline { 2 - 7 } & $21-30$ & $41-50$ & -.11 & .15 & .730 \\
\cline { 2 - 6 } & $31-40$ & $41-50$ & .11 & .16 & .761 \\
\hline \multirow{5}{*}{ Shared Vision } & $21-30$ & $31-40$ & -.062 & .07 & .645 \\
\cline { 2 - 6 } & $21-30$ & $41-50$ & $-.29\left(^{*}\right)$ & .12 & .032 \\
\cline { 2 - 6 } & $31-40$ & $41-50$ & -.23 & .13 & .146 \\
\hline
\end{tabular}

$* \mathrm{P}<.05$ significant

The two disciplines Mental Models and Shared Vision showed significance between the age group of 21-30 and $31-40$

Table 6: Post Hoc Tukey HSD for pairwise comparison among different experiences of participants on disciplines of peter Serge's model

\begin{tabular}{|l|l|l|l|l|l|}
\hline Dependent Variable & Experience (I) & Experience $(\mathrm{J})$ & Mean Diff. (I-J) & SE & $\mathrm{p}$ \\
\hline \multirow{4}{*}{ Shared Vision } & $<1$ & $2-5$ & -.11 & 0.08 & 0.557 \\
\cline { 2 - 6 } & $<1$ & $6-10$ & -.099 & 0.10 & 0.730 \\
\cline { 2 - 6 } & $<1$ & $>10$ & $-.368\left(^{*}\right)$ & 0.13 & 0.025 \\
\cline { 2 - 6 } & $2-5$ & $6-10$ & .01 & 0.08 & 1.000 \\
\cline { 2 - 6 } & $2-5$ & $>10$ & -.26 & 0.12 & 0.117 \\
\cline { 2 - 7 } & $6-10$ & $>10$ & -.27 & 0.13 & 0.155 \\
\hline \multirow{5}{*}{ Team learning } & $<1$ & $2-5$ & $-.27\left(^{*}\right)$ & 0.10 & 0.025 \\
\cline { 2 - 7 } & $<1$ & $6-10$ & $-.34\left(^{*}\right)$ & 0.12 & 0.018 \\
\cline { 2 - 7 } & $<1$ & $>10$ & -.33 & 0.16 & 0.142 \\
\cline { 2 - 7 } & $2-5$ & $6-10$ & -.06 & 0.09 & 0.911 \\
\cline { 2 - 7 } & $2-5$ & $>10$ & -.057 & 0.14 & 0.977 \\
\cline { 2 - 7 } & $6-10$ & $>10$ & .01 & 0.15 & 1.000 \\
\hline
\end{tabular}


The Post Hoc test shows that these two disciplines shared vision and Team learning are significant among the experiences of less than one year and one year to less than 10 years.

It must be noted that Shared Vision has shown outstanding values among both in age and experiences of preschool teachers. The Shared Vision discipline show more prominence among all the five disciplines of Peter Senge's Model. Team learning and Mental Model are significant in experiences and age of preschool teachers, respectively. Personal Mastery is also significant to some extent but System Thinking is least significant among both age and experience of the preschool teachers.

\section{FINDINGS \& CONCLUSION}

This section has elaborated the findings and outcomes of the research question according to the results drawn from data collection and analysis. Then a final conclusion is given in accordance with the research question and other various aspects of the research. The overall ANOVA value of the research showed good alpha value of 0.83 and proved to be reliable. The Post Hoc Tukey has shown where exactly the ANOVA is significant among all the five disciplines in different age groups and experiences. The research questions is being explained keeping in mind the ANOVA and Post Hoc test findings applied on both age and experience of preschool teachers along with the five disciplines of Peter Senge's Model of learning organization.

It should be noted that very few researches were found on the topic of learning organization in context of Pakistan. This study is an effort to introduce awareness about the significance of this concept. And it calls for a need to do more researches in the said area of education.

The findings of the survey are very simple and concise. Only one gender that is females and only preschool teachers were selected from only one private school chain of Lahore. The age and experience of teachers were taken as independent variable in the study. There was no restriction of age and experience to fill up the questionnaire. These results are shown in above tables.

The age is represented in three groups.

1- $\quad$ The data showed that 196 teachers out of 300 were of age $21-30$.

2- $\quad$ Second level of age is $31-40,82$ teachers fall in this age group according to the collected data.

3- $\quad$ Third level of age is $41-50$ and only 22 teachers are in this age group.

The experiences of the teachers were divided into 4 levels and the results are represented in descending order with preference to the maximum no of teachers falling in each level of experience.

1- The highest experience of most of the teachers is between 2- 5 years because 156 teachers fall in this level.

2- $\quad$ Second level is $6-10$ years and 63 teachers were from this level.

3- $\quad$ Third is less than one year or newly hired teachers and 58 teachers lie in this level.

4- $\quad$ The data showed that only 23 teachers fall in the category of above 10 years' experience of teaching in preschool.

The findings show that age and experience does matters in perceiving and understanding the concept of learning organizations but they are not the prime factors to determine understanding of learning organization. All the age groups and experience level have shown understanding of schools as a learning organization but understanding or perception of five disciplines show minimal existence. In preschool most of the teachers are youngsters and are willing workers but at the same time lack of experience can be a cause of less knowledge of five disciplines of a learning organization. It can be said that lack of higher education is the cause of lesser understanding of five disciplines but the qualification of teachers is not being checked in this research. The teachers play a vital role in running a school's system: in fact teachers are the integral part of the school. Good teachers can produce good earning experiences for students and produce productive individuals for the society.

Research Question: Whether age and experience of teachers has an impact on their perceptions of schools as learning organization?

There are so many researches about the impact of teacher's age and experience in the field of education. So, there are many contradictions in the results of those researches.

Age and experience does matter, but more is not always required in few cases. A few CALDER studies show that new and fresh teachers are not as much effective, on average than the teachers with few years of experience. (Clotfelter, Ladd \& Vigdor, 2007a, 2007b; Garris \& Sass, 2007; Kane, Rockoff, \& Staiger 2006; Ladd, 2008; Sass, 2007) 
A study in New York shows that teachers greatest productivity is noticed in their first few years of job, and their performance level weakens in later years and return in regards to experience seems to be diminished (Boyd et al 2007) Another research found that teachers show more growth and productivity in their first three years comparable to teacher having more experience (Hanushek, 2011)

The different findings of different researches show that age and experience are not factors to be ignored but they are not important to rely on because teachers may show difference of opinion at any age level and at any experience. Moreover, Learning is a continuous and a lifelong process but willingness to learn is also important. A teacher may be willing to learn and understand but facilities are not provided for learning or facilities are provided but teacher's willingness might be low. The impact of preschool teacher's age and experience is not found on the understanding of five discipline of Peter Senge' Model because the responses are not showing any difference with respect to age and experience. The data of this study showed that opinions of teachers are not changed in any age group or in any experience level. There is an understanding of five disciplines among all the age groups and experience level, the number of teachers from $31-40$ years of age are just 22 out of 300 i.e. $7 \%$ and 23 teachers out of 300 have more than 10 years of experience are 23 i.e. $8 \%$. But when we look at the responses we do not see any big difference of opinion or difference of agree or disagree due to age and experience. Moreover, any stress on any one discipline due to age and experience is not found. Though large numbers of teachers in preschool are young with less than 10 years of experience, still the older teachers did not show any marked difference. The larger response is only due to the majority of youngsters in preschool.

Whatever the age and experience of preschool teacher's is, it has no impact on the understanding of five disciplines of Peter Senge's Model. The quality of a good teacher does not only rely on age \& experience, there are many other factors and attributes to a good teacher. Purposeful improvement in the quality of education that students receive are determined by the quality of teacher regardless of age and experience (Anderson, 1991). Lastly, it can be said that all the teachers are aware of the concept of learning organization and they do perceive schools as a learning organization, age and experience are not considerable factors for judging the perception.

This research surely motivates the young future researchers to work more in the concept of learning organization as lesser attempts are done in Pakistan on this topic. The schools of Pakistan are already working at their best just a little effort is required to cope up with the international platform in the field of education. The schools of Pakistan are already a learning organization but a little more effort is also required to inculcate the concept of Peter Senge Model of five disciplines as many researches have proved that it is considered to be a perfect framework for any learning organization to run effectively and to sustain its success. In short, the main notion behind the concept of a learning organization is becoming smarter day by day because in the process of creating a learning organization, continuous learning is involved: a well-planned learning which is quite systematic and is in alignment with the needs and goals. Although, the five disciplines of Peter Senge to create schools as an ideal learning organization are challenging and hard to achieve but, indeed, important for the schools of Pakistan to meet up the international educational standards and to be tagged as perfect learning organization.

\section{REFERENCES}

1. Arygyris, C. (1990) Overcoming Organizational Differences: Facilitating Organisational Learning, Boston, MA: Allyn Bacon.

2. Arygyris, C. (1999) On Organizational Learning. Cambridge. Blackwell

3. Alma H. \& Michelle J. (2018) Leading Schools as Learning Organization

4. Bartell, S. M. (2001). Training's new role in learning organizations: Innovations in Education and Teaching International

5. Braham, B. (1995) Creating a Learning Organization, Menlo Park, CA: Crisp Publications.

6. Bratianu, C. (2015). Organizational Learning and the Learning Organization. Organizational Knowledge Dynamics: Managing Knowledge Creation, Acquisition, Sharing, and Transformation. Hershey, PA: Information Science Reference.

7. Cambron-McCabe, N., Lucas, T., Smith, B., \& Dutton, J. (2012). Schools that learn: A fifth discipline field book for educators, parents, and everyone who cares about education. Broadway Business.

8. Craig, K. (1940). "Mental models." Scottish journal. 
9. DeWitt, D. M., \& DeWitt, L. J. (2012). A case of high school hazing: Applying restorative justice to promote organizational learning. NASSP Bulletin.

10. Fullan, M. (2012), Change forces: Probing the depths of educational reform. Routledge.

11. Fullan, M. (2018) The Principal: Three Keys to Maximizing Impact. New Jersey: John Wiley \& Sons

12. Garvin, David A. (1993). "Building learning organizations", Harvard Business Review, Vol. 71 No.4, pp.70-4.

13. Garvin, D. A., Edmondson, A. C., \& Gino, F. (2008). Is yours a learning organization? Harvard business review, 86(3), 109.

14. Garvin, D. (1994). Building a Learning Organization, Business Credit, 96(1): 19-28. 1994 January.

15. George, D. Mallery, P. (2003). SPSS for Windows step by step: A simple guide and reference 11.0 update (4th edition)

16. Hodgkinson, M. (2000), Managerial perceptions of barriers to becoming a "learning organization": The Learning Organization.

17. Jones, A. M., \& Hendry, C. (1994), The learning organization: adult learning and organizational transformation. British Journal of Management.

18. Khasawneh, S. (2011). Learning organization disciplines in higher education institutions: An approach to human resource development in Jordan. Innovative Higher Education, 36(4), 273285.

19. Kristof, D., Jones, K., Patrick, D., \& Ramsey, J. (2007, May). Complex problems: What makes them complex and difficult to solve?. In 2007 International Symposium on Collaborative Technologies and Systems

20. Kools, M., and L. Stoll. (2016)"What Makes a School a Learning Organization?"

21. Leithwood, K. A., \& Hallinger, P. (Eds.). (2012). Second international handbook of educational leadership and administration (Vol. 8). Springer Science \& Business Media.

22. MacGregor, D. (1960). The human side of enterprise (Vol. 21, No. 166-171). McGraw-Hill: New York.

23. Miskel, C. G., \& Hoy, W. K. (2001). Educational administration: Theory, research, and practice.

24. Millet, B. (1998) Managing the processes of Organizational Change and Development : Study Book University of Southern Queensland.

25. Park, J. H. (2008). Validation of Senge's learning organization model with teachers of vocational high schools at the Seoul Megalopolis. Asia Pacific education review.

26. Cohen. L, Manion. L \& Morrison.K (2007), Research Methods in Education. - $7^{\text {th }}$ edition

27. Senge, P. (1990). The fifth discipline: The art and practice of the learning organization. New York, NY Currency Doubleday.

28. Senge, P. M. (1994c). Senge's five disciplines for learning organizations. Personnel Journal, 73 (11), 66.

29. Senge, P. M. (1994a). The laws of the fifth discipline. In The Fifth Discipline (pp. 57-67). New York: Currency Doubleday

30. Senge, P. M., Cambron-McCabe, N., Lucas, T., Smith, B., \& Dutton, J. (2012). Schools that learn (updated and revised): A fifth discipline fieldbook for educators, parents, and everyone who cares about education. Crown Business.

31. Somekh, B. (2009). The SAGE handbook of educational action research. Sage Publications.

32. "Systems Approaches to Management", Springer Nature America, Inc, 2002

33. Tomlinson, H. (2004). Educational leadership: Personal growth for professional development (Vol. 3). Sage. 